\title{
Feasibility and acceptance of electronic monitoring of symptoms and syndromes using a handheld computer in patients with advanced cancer in daily oncology practice
}

\author{
D. Blum • D. Koeberle • A. Omlin - J. Walker • \\ R. Von Moos • W. Mingrone $\cdot$ S. deWolf-Linder • \\ S. Hayoz • S. Kaasa • F. Strasser • K. Ribi
}

Received: 26 September 2013 / Accepted: 4 March 2014 /Published online: 5 April 2014

(C) Springer-Verlag Berlin Heidelberg 2014

\begin{abstract}
Purpose We investigated the feasibility and acceptance of electronic monitoring of symptoms and syndromes in oncological outpatient clinics using a PALM (handheld computer). Methods The assessment of a combination of symptoms and clinical benefit parameters grouped in four pairs was tested in a pilot phase in advanced cancer patients. Based on these experiences, the software E-MOSAIC was developed, consisting of patient-reported symptoms and nutritional intake and objective assessments (weight, weight loss, performance status and medication for pain, fatigue, and cachexia). EMOSAIC was then tested in four Swiss oncology centers. In order to compare the methods, patients completed the EMOSAIC as a paper and a PALM version. Preferences of version and completion times were collected. Assessments were compared using Wilcoxon signed-rank tests, and the test-retest reliability was evaluated.
\end{abstract}

D. Blum $\cdot$ A. Omlin $\cdot$ J. Walker $\cdot$ S. deWolf-Linder $\cdot$ F. Strasser Oncological Palliative Medicine, Oncology, Dept. Internal Medicine \& Palliative Center, Cantonal Hospital, St. Gallen, Switzerland

D. Koeberle

Oncology, Dept. Internal Medicine, Cantonal Hospital, St. Gallen, Switzerland

R. Von Moos

Kantonsspital Chur, Chur, Switzerland

W. Mingrone

Kantonsspital Aarau, Aarau, Switzerland

S. Hayoz

SAKK Coordinating Center, Bern, Switzerland
Results The pilot phase was completed by 22 patients. Most patients and physicians perceived the assessment as useful. Sixty-two patients participated in the feasibility study. Twelve patients reported problems (understanding, optical, tactile), and five patients could not complete the assessment. The median time to complete the PALM-based assessment was $3 \mathrm{~min}$. Forty-nine percent of patients preferred the PALM, $23 \%$ preferred a paper version, and $28 \%$ of patients had no preference. Paper vs. PALM revealed no significant differences in symptoms, but in nutritional intake $(p=0.013)$. Test-retest (1 h, $n=20)$ reliability was satisfactory $(r=073-98)$. Conclusion Electronic symptom and clinical benefit monitoring is feasible in oncology outpatient clinics and perceived as useful by patients, oncology nurses, and oncologists. E-MOSAIC is tested in a prospective randomized trial.

\footnotetext{
S. Kaasa

European Palliative Care Research Centre, Faculty of Medicine, Norwegian University of Science and Technology (NTNU), Trondheim, Norway

K. Ribi

Quality of Life Office, IBCSG Coordinating Center, Bern, Switzerland

J. Walker

Elsevier Health Analytics, Berlin, Germany

Present Address:

D. Blum $(\square)$

European Palliative Care Research Centre, Faculty of Medicine,

Norwegian University of Science and Technology (NTNU),

Trondheim, Norway

e-mail: david.blum@ntnu.no
} 
Keywords Symptom assessment · Clinical benefit . Computer $\cdot$ Feasibility

\section{Introduction}

Patients with advanced, incurable cancer suffer from a variety of symptoms such as pain, depression, or appetite loss. These physical or psychological symptoms as well as nutritional problems are often underestimated due to poor detection in daily practice [22]. Furthermore, oncologists' perceptions of patients' symptoms often differ from patient-reported experiences [15]. An important focus of treatment in this patient population is to achieve an improvement in health-related quality of life (HRQL) [26]. Medical oncologists considered HRQL as the most important outcome in assessing the effect of palliative chemotherapy [16]. However, physicians' decisions regarding modification of palliative chemotherapy after a patient consultation were weakly associated with their considerations of HRQL [11].

Due to time pressure in daily practice and the multitude of possible assessment parameters, several investigators attempted to facilitate assessment by using computer-assisted technology. The first studies assessed whether the computerized collection of HRQL data is possible and whether the provision of these data to oncologists improved patientoncologist communication and symptom control [32]. Collection of symptoms or HRQL information of patients by touch pad devices in the waiting room were found to be feasible and useful to identify discrepancies of patients' and health care professionals' symptom assessment [30]. In oncology, there is increasing evidence that computerized assessment is feasible, including patient-reported outcome parameters covering Qol data [7, 10, 28] or symptoms [8, 24, 31].

A meta-analysis of studies in diverse clinical settings indicated that computer-based assessment of patient-reported outcomes is equivalent to paper-based assessment, but equivalence needs to be confirmed when developing new tools [17].

Although existing studies emphasize the importance of patient reported outcomes such as HRQL for improved symptom assessment and communication, this information can only insufficiently guide treatment decisions of oncologists in daily practice [12]. The effect of systemic anticancer therapy is commonly monitored by tumor response and toxicity assessment, which are measured by gold standards (i.e., RECIST, CTCAE). Furthermore, anticancer treatment in palliative intention can alleviate cancer-related symptoms even in the absence of a tumor size response [13] while in some patients, the reduction of tumor size does not necessarily imply a benefit for the patient [23]. Therefore, a combination of objective clinical measurements and patient-reported symptoms is used to guide anticancer therapy in the non-curative setting, which can be conceptualized as syndromes or clinical benefit parameters. In pancreatic cancer for instance, the endpoint clinical benefit response (a composite assessment of pain, pain medication intake, performance status, and weight) has become an outcome parameter to assess the impact of anticancer therapy on tumor-related symptoms [3]. Close monitoring of both, patient-reported symptoms and clinical benefit parameters (as objective indicators of disease control), are therefore helpful to guide treatment during anticancer treatment in palliative intention, in addition to tumor response and toxicity information. We hypothesized that the availability of simultaneously assessed patient-reported symptoms and clinical data could improve patient care.

We developed a computer-based assessment tool covering both common symptoms and clinical benefit parameters for patients with advanced incurable, symptomatic cancer and tested its feasibility and acceptance in the setting of daily oncology outpatient clinics.

\section{Methods}

The development process and feasibility testing was performed in three phases in order to allow continuous modifications between the steps. First, a paper-based pilot phase was performed at a single institution. Based on this experience, a pilot software called "E-MOSAIC" (electronic monitoring of symptoms and syndromes associated with advanced cancer) for a handheld computer (PALM) was developed and pretested in two institutions. Second, a feasibility study with the PALM was carried out in four centers. Third, a survey among oncologists about barriers using a computerized assessment system was performed.

\section{Inclusion criteria of patients and physicians}

Eligible patients had advanced incurable solid cancer of any type and were about to be treated with an anticancer therapy with an expected tumor response rate below $20 \%$ based on the literature. Any weekly to biweekly or continuous antineoplastic treatment schedule, which required weekly visits, were allowed. Patients had to have symptomatic disease, defined as any symptom score $\geq 3 / 10$ on the Edmonton Symptom Assessment Scale (ESAS) [6]. Eligible oncologists were required to be experienced in medical oncology defined as certified specialists or more than two years of training in medical oncology, and all doctors had to be familiar with communication skills, defined as completion of a basic communication skills course or an equivalent training.

Phase 1: paper-based pilot and development of E-MOSAIC

In the first phase, the paper-based symptom assessment system was used in daily oncology practice. Immediately, before 
each physician visit, the patient completed the ESAS on paper on three consecutive visits. The completed ESAS sheets were then handed out to the treating oncologists. They were asked to acknowledge the ESAS during the consultation and transfer the values onto the patient monitoring sheet (PMS). The PMS contained the four pairs of symptoms and clinical benefit parameters (pain/analgesics, fatigue/Karnofsky performance status (KPS), anorexia/weight loss, depression/antidepressants). As an outcome, the compliance of patients with the paper version was assessed. The experiences of involved physicians were assessed using the following questions: (1) Was the clarity of treatment goal improved by the ESAS or not, and if yes, how?, (2) What adaptations in the monitoring sheet would be necessary for improvement?, (3) Whether they believed that the novel monitoring system of symptoms improved patients' quality of life or not, and if yes, how?, (4) To estimate the impact on their usual consultation time, and (5) To provide an overall judgment of the feasibility of the intervention on daily oncology practice.

\section{Development of E-MOSAIC}

A computer-based version of the assessment was developed for a PALM within the study team, consisting of one to two nurses per center and the main investigators (MDs: specialists in palliative medicine, medical oncology, and information technology). In order to minimize contamination, only one oncologist per center was involved, mainly for supervision, but with minimal involvement in the instrument development process.

For refining purposes, the team decided to add symptoms other than the ones assessed by ESAS and to add any medications used for symptoms and syndromes other than pain. Various response formats (visual analog scales, numerical scales, checklists) and different electronic solutions (PALM, flat-PC, touch screen computers) were evaluated. The wording of the questions and the visual appearance (screenshots) was coordinated with the quality of life office of the Swiss Group for Clinical Cancer Research (SAKK). The experiences of using the first PALM version with a few patients were collected and transferred by fax or email to the study center. The proposals for refinement of the assessments were reviewed weekly by the investigators, the nurses, and the IT specialist. Those adaptations that seemed necessary were prioritized. After significant changes, readjusted palm computers were sent to the participating centers. The teams also suggested how to adapt procedures in the outpatient setting to facilitate the E-MOSAIC assessment in routine practice (patients, weight assessment by nurses not doctors, printer procedures). Based on these processes, we developed the PALMbased E-MOSAIC assessment.

\section{Final E-MOSAIC assessment tool}

E-MOSAIC consisted of three elements, which were completed at every visit, element $P$ by the patient and elements $G$ and $\mathrm{M}$ with assistance of the nurses or study personnel. A screenshot of the E-MOSAIC pain assessment is displayed in Fig 1.

Element P: visual analog scales (VAS) 1-10 of the following:

(a) Nine frequent symptoms (pain, fatigue, drowsiness, nausea, anxiety, depression, shortness of breath, loss of appetite, overall well-being);

(b) Up to three optional symptoms (from a list of 20);

(c) Patients' estimated nutritional intake;

Element G:

(a) Actual body weight and height;

(b) Actual Karnofsky performance status (KPS);

(c) Weight loss, body mass index calculated automatically, at baseline only;

Element M: predefined, simplified list of concomitant medications for the following:

(a) Pain (NSAIDS, Opioids [electronic algorithm to deliver the morphine equivalent daily dose]);

(b) Fatigue (erythropoietin, methylphenidate);

(c) Anorexia/cachexia (progestins, procinetics).

After completion of the PALM-based assessments the data was transferred immediately from the docking station onto the local computer. A longitudinal monitoring sheet (LoMoS) was created electronically, printed in less than $30 \mathrm{~s}$, and added on top of the patients' file notes. The LoMoS is displayed in Fig 2. Physicians were required to have the file notes present before examining the patients.

The LoMoS was structured as follows:

(a) VAS pain and pain medication (opioids calculated as morphine-equivalent daily dose, other analgesics);

(b) VAS fatigue and KPS, medication for fatigue;

(c) VAS anorexia, weight change, interventions for anorexia;

(d) Individual symptoms;

(e) Clinical benefit (combination of pain, pain medication, and weight).

All patients completed the paper and the PALM version of the assessment and entered demographic information, including prior experience with computers.

The final E-MOSAIC included three components: (1) a handheld application running on a Palm, (2) a synchronization software running on a Windows desktop PC to synchronize 
Fig 1 Examples of a visual analog scale for pain. a Blank. b Filled out by the patient
eMosaic

Wie ist es Ihnen in den letzten 24 Stunden gegangen?

\section{Schmerz}

Kein $\begin{gathered}\text { Schlimmst } \\ \text { möglicher }\end{gathered}$

一
eMosaic

Wie ist es Ihnen in den letzten 24 Stunden gegangen?

\section{Schmerz}

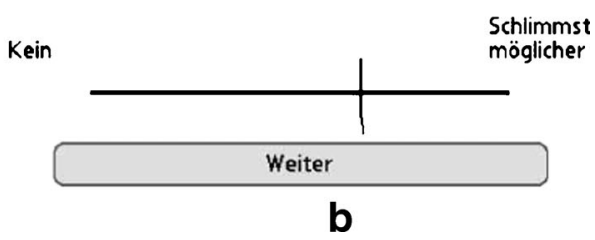

a

E-MOSAIC: longitudinal electronic monitoring of symptoms and syndromes associated with advanced cancer in patients treated with chemotherapy in palliative intention.

SAKK

Name:

geb:
UPN:
Sex:
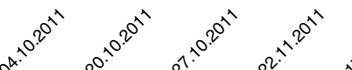

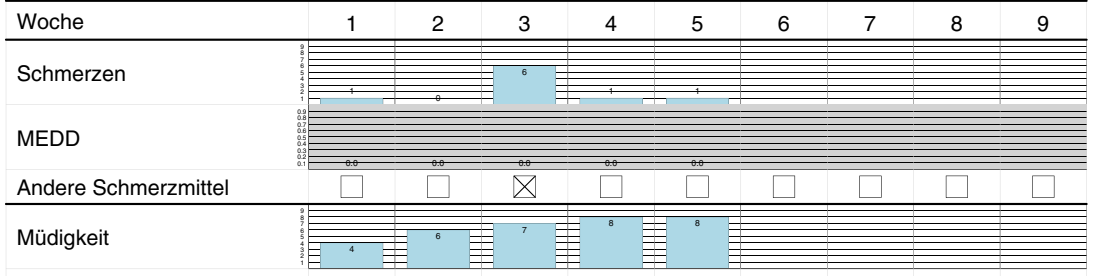

KPS

80

80

Methylphenidate

Erythropoitin

Appetit

Nahrungsaufnahme

Gewichtsveränderung

Gewicht

Ernährungstherapie

Progestine

Prokinetika

Diuretika gegen Ödeme

Hustenmittel

$\begin{array}{lll}\square & \square \quad \square \quad \square \quad \square\end{array}$

Übelkeit

Depression

Angst

Schwindel

Schläfrigkeit

Wohlbefinden

Atemnot

Energielosigkeit

Heiserkeit

Ungewissheit
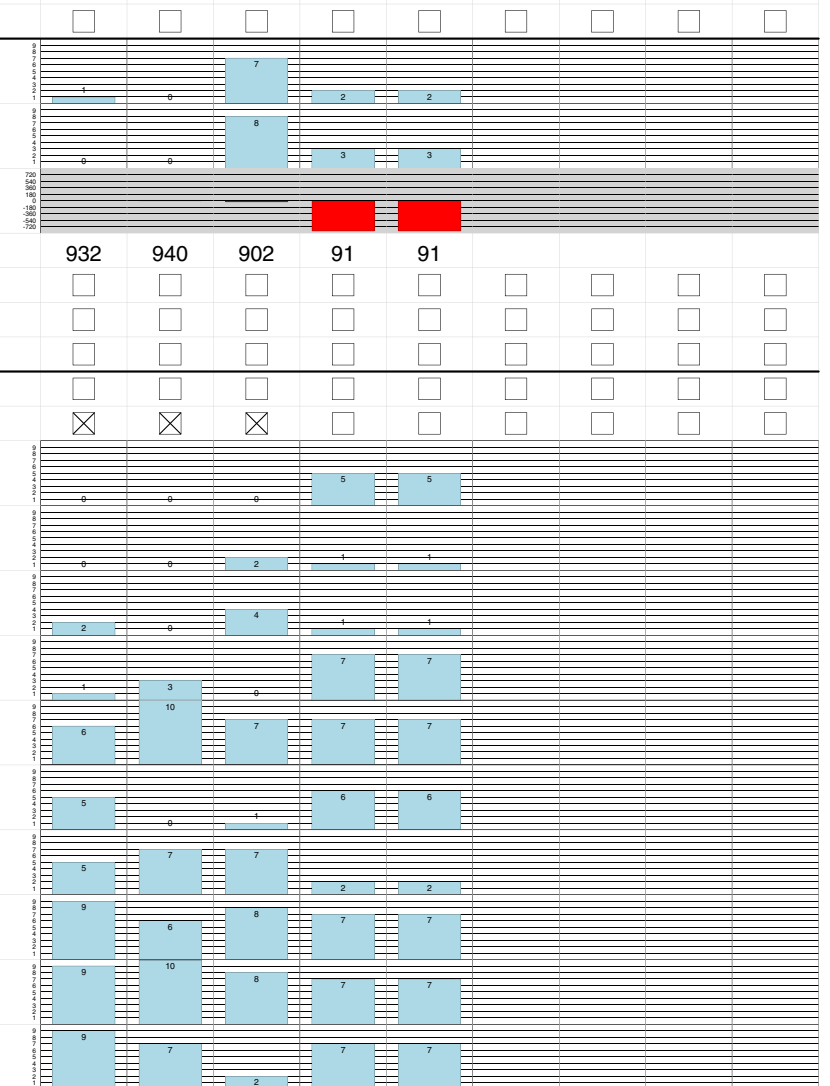

Fig 2 Longitudinal monitoring sheet (LoMoS) 
patient master data and to pull the gathered data (elements $\mathrm{P}$, $\mathrm{G}$, and $\mathrm{M}$ ) from the handheld device to save it on a data storage on the desktop $\mathrm{PC}$, and (3) a reporting software running on a desktop PC to build and print the LoMoS.

The handheld application was developed in a $\mathrm{C}++$ program with the open source Palm OS software development kit (Palm OS version 5.3) to run on Palm PDAs. The synchronization between the PDA and desktop PCs was achieved by a HotSync conduit. This was again programmed in $\mathrm{C}++$ with the open source Palm conduit software development kit. The LoMoS was generated as a PDF (portable document format) file using a self-developed Python script and the Reportlab Toolkit. The PDF file could be viewed on screen or printed.

Phase 2: feasibility study

Physicians', nurses' and patients' preferences, experiences, and perceived usefulness were assessed by a questionnaire, which was developed by an interdisciplinary group of physicians and nurses and tested for face validity. Time needed to explain how to use the PALM-based assessment and time needed to complete the assessment was measured.

The reliability of the PALM-based assessment was tested by comparing paper and PALM-based assessment of symptoms using Wilcoxon signed-rank tests. For test-retest reliability of the PALM-based assessment after one hour, Pearson correlation coefficients were used in a convenience sample. Patients who were not experiencing significant change of their symptoms within the hour as judged by the nurse or oncologist were eligible.

No formal sample size estimation was performed, but in order to have a representative sample, it was planned to accrue at least 10 patients from at least two oncologists at each of five or more SAKK centers (total $\geq 50$ patients).

Phase 3: oncologists' survey

To explore potential barriers for implementing a randomized trial with E-MOSAIC, the core study team collected potential topics by discussions. Randomly selected physicians (two senior oncologists, two junior oncologists, two palliative care physicians working in the oncology department) were asked in a focus group the question of potential barriers for conduct of a randomized trial with six consecutive weekly visits using E-MOSAIC assessments compared to standard of care. In a qualitative thematic analysis of the focus group's field notes, three main barriers relating to study, patients, and feasibility were identified. Questions for the survey (see Appendix) were prepared and grouped according to these three major topics. The final version of the survey was mailed to oncologists of different cancer centers in Switzerland. Multiple answers and comments in free text were possible. The responses were
Table 1 Demographics of patients of the pilot phase

Patients $(n=22)$

Sex

Male $\quad 14(64 \%)$

Female $\quad 8(36 \%)$

Age (years), median (range) $62(42-75)$

Tumor types

Colorectal and anal $\quad 9(41 \%)$

Pancreatic, bile duct $\quad 4(18 \%)$

Upper GI

Head and neck

Other (prostate, sarcoma)

$3(14 \%)$

$4(18 \%)$

$2(9 \%)$

Chemotherapy

Continuous treatment (capecitabine, gefitinib)

$6(27 \%)$

Weekly treatment (gemcitabine, irinotecan, carboplatin/paclitaxel, docetaxel)

Biweekly treatment (oxaliplatin, with 5-FU)

$13(59 \%)$

$3(14 \%)$

$23(3-106)$

$4(0-8)$

Pain at baseline (VAS), median (range), $n=21$

Pain syndromes

Incident

$9(41 \%)$

Neuropathic

$3(14 \%)$

Psychological distress

More than one of the three pain syndromes

Missing

$5(23 \%)$

$4(18 \%)$

$2(9 \%)$

$6(2-10)$

Fatigue at baseline (VAS), median (range), $n=21$

Fatigue syndromes

Cognitive fatigue (delirium)

Emotional fatigue (depression)

$9(41 \%)$

$6(27 \%)$

Physical fatigue (asthenia)

$19(86 \%)$

More than one of the three fatigue syndromes

$9(41 \%)$

$5(1-10)$

Anorexia at baseline (VAS), median (range)

Anorexia/cachexia syndromes

No anorexia and no cachexia

$4(18 \%)$

Primary anorexia (paraneoplastic)

$15(68 \%)$

Primary cachexia (paraneoplastic)

$13(59 \%)$

$6(27 \%)$

nutritional intake)

Secondary cachexia (starvation)

$4(18 \%)$

$3(14 \%)$

$4(18 \%)$

$1(5 \%)$

$1(0-9)$

Shortness of breath at baseline, (VAS), median (range), $n=21$

Respiratory syndromes

Presence of hypoxemia, defined as $<92 \%$ at rest, no $\mathrm{O}_{2}$

Obstruction requiring steroids

$1(5 \%)$

$0(0 \%)$

Cachexia with severe muscle loss

$3(14 \%)$

Pulmonary infection

$0(0 \%)$

Cardiac failure 
anonymised and analysed using descriptive statistics according to the three main categories.

Ethical considerations

A protocol was written in accordance with the seven universal requirements for ethical clinical research [14]. The study was performed in accordance with the Declaration of Helsinki and the guidelines of Good Clinical Practice. All parts of the study were approved by the local ethics committee.

\section{Results}

Paper-based pilot

The pilot included 22 patients with various tumor types. Demographic and clinical data are summarized in Table 1. All patients completed all three required ESAS sheets. For all

Table 2 Demographics of patients in the feasibility part

\begin{tabular}{|c|c|}
\hline & Patients $(n=62)$ \\
\hline \multicolumn{2}{|l|}{ Sex } \\
\hline Male & $31(50 \%)$ \\
\hline Female & $31(50 \%)$ \\
\hline Age (years), median (range) & $63.5(23-86)$ \\
\hline \multicolumn{2}{|l|}{ Tumor types } \\
\hline Colorectal and anal & $12(19 \%)$ \\
\hline Pancreatic, bile duct & $2(3 \%)$ \\
\hline Lung cancer & $4(6 \%)$ \\
\hline NHL/Hodgkin/leukemia & $16(26 \%)$ \\
\hline Breast cancer & $11(18 \%)$ \\
\hline Other (prostate, sarcoma) & $11(18 \%)$ \\
\hline Not specified & $6(10 \%)$ \\
\hline Metastatic disease & $48(77 \%)$ \\
\hline \multicolumn{2}{|l|}{ Main symptoms ${ }^{\mathrm{a}}$} \\
\hline Pain & $16(26 \%)$ \\
\hline Fatigue & $31(50 \%)$ \\
\hline Nausea & $4(6 \%)$ \\
\hline Anorexia & $11(18 \%)$ \\
\hline Anxiety & $7(11 \%)$ \\
\hline Depression & $2(3 \%)$ \\
\hline Shortness of breath & $4(6 \%)$ \\
\hline Dizziness & $5(8 \%)$ \\
\hline Dry mouth & $8(13 \%)$ \\
\hline Others $^{\mathrm{b}}$ & $40(65 \%)$ \\
\hline No symptoms & $2(3 \%)$ \\
\hline Not reported & $2(3 \%)$ \\
\hline
\end{tabular}

${ }^{a}$ Choice of three symptoms (free text) most patients interviewed by nurses

${ }^{\mathrm{b}}$ Symptoms occurring in six or less patients (e.g., dysphagia, sweating)
Table 3 Patients' results of the feasibility part

Patients $(n=57)$

Time needed to complete E-MOSAIC with PALM

Less than $2 \mathrm{~min}$

$17(30 \%)$

Between 2 and 5 min

$23(40 \%)$

More than $5 \mathrm{~min}$

$17(30 \%)$

Time needed to complete the symptom assessment by paper ${ }^{\mathrm{a}}$

Less than $2 \mathrm{~min} \quad 44(77 \%)$

Between 2 and 5 min $\quad 6(11 \%)$

More than 5 min $2(4 \%)$

Difficulties with completion of E-MOSAIC

Optical problems $\quad 4(7 \%)$

Tactile problems $\quad 2(4 \%)$

Problems of understanding $\quad 6(11 \%)$

Did not E-MOSAIC $\quad 5(9 \%)$

Other unspecified $\quad 0(0 \%)$

No difficulties reported $\quad 45(79 \%)$

Preference for PALM or paper

Paper version $\quad 13(23 \%)$

PALM version $28(49 \%)$

No preferences $\quad 16(28 \%)$

Experience with computer $^{\mathrm{b}} \quad n=28$

Experience with computers $\quad 7(25 \%)$

No experience with computers $\quad 9(32 \%)$

Little experience with computers $\quad 12(43 \%)$

${ }^{\mathrm{a}}$ Including only main symptoms and estimation of nutritional intake

${ }^{\mathrm{b}}$ Questions asked only subgroup

but one patient, the physicians completed the patient monitoring sheets. In $77 \%$ of patients, the treating physicians perceived the novel symptom monitoring as useful for the daily oncology practice. The benefit of having a longitudinal and quantitative overview of symptoms was mentioned as positive aspect. In $95 \%$ of the patients, oncologists reported an improved communication with the use of PMS, with relatives in $85 \%$, with other oncologist in $75 \%$, with other health care professionals in $80 \%$, and with referring physicians in $63 \%$.

In $95 \%$ of the cases, the physicians perceived clarity of goals of treatment as improved, with a specific focus on symptom control. In $76 \%$ of the cases, the impact of the intervention on patients' quality of life was perceived as beneficial. The reasons were better control of overall symptom load (81\%), pain (86\%), fatigue (61 \%), weight loss (38\%), or respiratory symptoms (38\%). A positive clinical impact of the assessment was seen by the physicians for the symptoms such as pain in $94 \%$, fatigue in $70 \%$, weight loss in $75 \%$, and respiratory problems in $33 \%$ of the patients.

Eighty percent of the patients perceived the assessment as useful. However, the necessity to complete the PMS by hand was perceived as too time consuming for daily oncology practice, the reason why an electronic solution was developed. 
Table 4 Health care professionals' results of the feasibility part

Patients $(n=60)$

$\begin{array}{ll}\text { Time needed by nurses } & \\ \text { to explain PALM E-MOSAIC } & 42(70 \%) \\ \text { Less than } 2 \text { min } & 12(20 \%) \\ \text { Between } 2 \text { and } 5 \text { min } & 5(8 \%) \\ \text { More than } 5 \text { min } & 1(2 \%) \\ \text { Missing } & \\ \text { Time needed by nurses to complete data }{ }^{a} & 56(93 \%) \\ \text { Less than } 2 \text { min } & 2(3 \%) \\ \text { Between } 2 \text { and } 5 \text { min } & 2(3 \%) \\ \text { More than } 5 \text { min } & \\ \text { Preference of nurses of PALM or paper } & 1(2 \%) \\ \text { Paper version } & 44(73 \%) \\ \text { PALM version } & 13(22 \%) \\ \text { No preferences } & 2(3 \%) \\ \text { Missing } & \end{array}$

${ }^{\text {a }}$ For example, weight, KPS, and medications

Feasibility study

The PALM-based E-MOSAIC assessment system was explored in 62 patients with various tumor types. All demographic and clinical variables are summarized in Table 2. Fifty-two patients completed the symptom assessment on paper, which included only the nine main symptoms and the estimation of nutritional intake. The majority of patients required less than $2 \mathrm{~min}(n=44)$ to complete the questionnaire with six patients requiring more than three, and two patients more than $5 \mathrm{~min}$.

The time needed by the nurses to explain the E-MOSAIC PALM assessment to patients $(n=59)$ was less than 2 min in 42 patients, more than $3 \mathrm{~min}$ in 12 , and more than $5 \mathrm{~min}$ in 5 patients. Seventeen patients needed less than $2 \mathrm{~min}$ to

Table 5 Barriers in implementing a trial with E-MOSAIC

Patient related factors

I don't see patients regularly on a weekly basis

I don't see enough patients matching the inclusion criteria

I am taking turns with other oncologists in treating the patients

Study

I think inclusion in such a study is difficult due to procedural reasons

The benefit of such as study is not clear

I don't see a role for computers in the treatment of patients

Feasibility

No time for additional tasks in clinic

I was involved in the tests and the printer did not work complete E-MOSAIC, 23 more than $3 \mathrm{~min}$, and 17 more than 5 min (see Table 3).

Difficulties with completion of the E-MOSAIC assessment were observed in 12 patients (19\%), of whom 4 patients had optical, 6 understanding and 2 patients had tactile problems, and 5 of $62(8 \%)$ patients did not complete the full EMOSAIC assessment.

Of the 57 evaluable patients, 13 (23\%) patients preferred the paper-based assessment of main symptoms, and $28(49 \%)$ patients preferred the PALM-based assessment, $16(28 \%)$ patients had no preference. Nurses $(n=10)$ did judge for each patient which tool they preferred. For 58 patients, the nurses preferred the PALM in 44 cases $(76 \%)$, in 13 cases $(22 \%)$ they had no preferences, and in 1 case they preferred the paper version (Table 4).

Wilcoxon signed-rank tests showed no significant differences of PALM vs. paper of 9 symptoms ( $p$ values: 7 symptoms 0.249-940, well-being 0.089, dyspnea 0.060). For nutritional intake, a significant difference was found ( $p$ value $0.013)$. The median $(0-100)$ was 26 , SD 30 on paper vs. 34 SD 31 on palm. Test-retest $(1 \mathrm{~h}, n=20)$ reliability of nine symptoms and nutritional intake assessed by Pearson correlation coefficients was in a satisfactory range $(r=0.73-0.98)$.

\section{Survey of oncologists}

The questionnaire was mailed to 36 oncologists, of which 18 (50\%) replied. Twelve were male, the average age was 37 years, and the average work experience was 4 years. Continuity of care, reservations against computer technology or research in general were the main barriers. The specific quantification of concerns is provided in Table 5. Specific answers added in free text were: "Palliative care patients have to fill in enough assessment forms already" and "I appreciate if the nurses perform the study."

\section{Discussion}

$n$ Electronic symptom and clinical benefit parameter monitoring proved to be feasible and was perceived as useful for oncological outpatient management in Switzerland. Patient and 12 health care professionals generally accepted E-MOSAIC by 8 PALM. The completion rate in a multicenter setting was high.

8 In accordance to these results, a range of studies demonstrated the feasibility of self-assessments in patients with

13 advanced, incurable cancer for various symptom assessment 2 tools [15]. Velikova et al. compared touch screen question-

1 naires with paper questionnaires for collecting data on quality of life in oncological inpatients and showed that $52 \%$ of

2 patients preferred the touch screen to a paper version [29].

1 Dearney evaluated the acceptability of using handheld computers for symptom assessment in patients receiving 
chemotherapy. Most patients (66 \%) had little previous computer experience, and $74 \%$ of patients stated that the symptom information would help in self-care and symptom management [21].

There is evidence that computer-based assessment is feasible over a long period and from home: in a Norwegian randomized controlled trial, a computer-assisted interactive tailored patient assessment tool was repeatedly used to measure symptoms up to one year [27]. In another study, patients were invited to report symptoms on an online platform from home. One hundred twenty-five patients who received chemotherapy were invited, 105 participated and showed a high compliance and satisfaction with the system [2]. A randomized controlled trial tested the effect of the electronic selfreport assessment cancer (ESRA-C) in 660 cancer patients at two centers. The output from the ESRA-C was displayed to the treatment team. The primary outcome was the likelihood of discussion of symptoms and quality of life issues (SQLIs) between clinicians and patients. When the SQLIs were rated as problematic, they were more discussed during the visits, and the output was perceived as useful by clinicians [4]. In a large international study, 1,017 cancer patients with incurable metastatic or locally advanced disease from 17 centers in eight countries reported on pain, depression, and physical function using a touch screen laptop computer. The entire assessment was completed by over $90 \%$ of the patients, some of them with far advanced disease [18]. These results document the general acceptance of computer assessment by patients in various settings. In a recent publication, it was once more highlighted that computer technology is a possibility to integrate HRQL information into routine oncology [19].

Limitations of our study include the fact that our results may be biased by a selective sample of patients who were fitter or who had more computer experience; however, we used a convenient sample without tracking patients with better health status. In addition, results on acceptability might have been biased by patients' willingness to provide positive responses. The age of patients varied widely in our sample and mirrors the general oncology outpatient population [19]. Because patients had to learn how to use the system and are seen by the nursing staff before consultation with the physician, we decided to offer nursing support to complete the assessments, which may have influenced the outcomes towards better acceptance.

The electronic device in our study was a PALM. It was chosen at the time because it could be handed out to patients and they were able to complete the assessment with assistance of nurses (e.g., weight) while waiting for blood results and doctor examination. Meanwhile, this device unfortunately went out of production. We did not compare other electronic tools with bigger screens to the PALM. Problems of understandability, visual, and tactile problems need to be addressed, and assistance when handling the device should be in place, especially when developing computer-based assessment systems on small devices for an aging and sick population. The quantification of nutritional intake on a visual analog scale might be less accurate on small devices. Velikova and Detmar utilized large touch screens in the waiting room where confidentially issues may arise and patients might be too sick to stand up and reach the touch screens [12, 29].

Assessment instruments have the immanent potential to facilitate but as well the danger to hamper routine care. Gatekeeping or objections against computer technology from health care professionals might be a challenge in implementing such approaches: in a recent publication, only one out of 17 clinicians allowed lung cancer patients to take part in a computerized symptom assessment study because of concerns about the burden it induces to vulnerable patients [9]. However, current evidence suggests that symptom assessments may increase communication, if the information is displayed to patient and physician. (15) Gatekeeping can be overcome, if clinicians become aware of the benefit of computerized systems [1]. A device is only used if it is of any help to the staff and accepted by patients. Involvement of users (patients and health care providers) during the development and testing for effectiveness is therefore essential [25].

Our work may help to increase the assessment of symptoms and clinical benefit parameters in daily practice [20]. The pragmatic approach may support oncologists who typically work with limited time resources to elicit and to quantify each patient's individual symptoms. Future research needs to also ask the question if the provision of symptom and clinical benefit data will have an impact on the work of oncologists and on patient care.

Overall, the E-MOSAIC tool shows good acceptance and sufficient test-retest reliability compared to a paper version. Based on these results, it was used in SAKK 95/06, a large phase III trial in three languages regions (German, French, and Italian) in Switzerland [5].

Acknowledgments The study is supported by a SAKK pilot project grant and by unrestricted grants from six pharmaceutical companies, namely Amgen, Bristol-Myers Squibb, Grünenthal, Janssen Cilag, Roche, and Sanofi-Aventis. We thank the nursing staff of the participating institutions for their contribution: Hess J. and Wiedmer S. of Oncological Palliative Medicine, Oncology, Dept. Internal Medicine \& Palliative Center, Cantonal Hospital, St. Gallen, Switzerland; Stoll H. R. of University Hospital Basel, Basel, Switzerland; and Manetsch G. of Kantonsspital Chur, Chur, Switzerland. EURO IMPACT is funded by the European Union Seventh Framework Programme (FP7/2007-2013, under grant agreement $\mathrm{n}^{\circ}$ [264697]).

Conflict of Interest The authors do not have a personal financial relationship with the organizations that sponsored the research. R Von Moos and F. Strasser had advisory roles and received unrestricted grants according to the disclosure form. The authors have full control of all primary data and agree to allow the journal to review their data if requested. 


\section{Appendix}

\section{Barriers questionnaire}

\section{Study}

The study is unclear.

The study is too extensive.

I don't believe in such a study.

My focus is on therapy not studies.

I don't see benefit in non-therapy associated studies.

I don't believe in nurse led studies.

\section{Patients}

I don't want to bother patients.

I don't treat such patients.

My patients are not able to fill in palm based assessments.

I don't see patients on a weekly basis.

My patients are in other studies.

\section{Feasibility}

I do not want to address palliative care issues.

My patients do not suffer from symptoms.

I don't see patients on a regularly basis.

I was involved in the tests, and it was too complicated.

I don't believe that computers are helpful.

I have no time for additional tasks in clinic.

I was involved in the tests and the printer did not work.

\section{References}

1. Abernethy AP, Currow DC (2011) Patient self-reporting in palliative care using information technology: yes, there is hope! Palliat Med 25: 673-674

2. Basch E, Iasonos A, Barz A, Culkin A, Kris MG, Artz D, Fearn P, Speakman J, Farquhar R, Scher HI, McCabe M, Schrag D (2007) Long-term toxicity monitoring via electronic patient-reported outcomes in patients receiving chemotherapy. J Clin Oncol 25:53745380

3. Bernhard J, Dietrich D, Scheithauer W, Gerber D, Bodoky G, Ruhstaller T, Glimelius B, Bajetta E, Schuller J, Saletti P, Bauer J, Figer A, Pestalozzi BC, Kohne C-H, Mingrone W, Stemmer SM, Tàmas K, Kornek GV, Koeberle D, Herrmann R (2008) Clinical benefit and quality of life in patients with advanced pancreatic cancer receiving gemcitabine plus capecitabine versus gemcitabine alone: a randomized multicenter phase III clinical trial-SAKK 44/00CECOG/PAN.1.3.001. J Clin Oncol 26:3695-3701

4. Berry DL, Blumenstein BA, Halpenny B, Wolpin S, Fann JR, Austin-Seymour M, Bush N, Karras BT, Lober WB, McCorkle R (2011) Enhancing patient-provider communication with the electronic self-report assessment for cancer: a randomized trial. J Clin Oncol 29:1029-1035

5. Blum D, Koeberle D, Ribi K, Hsu Schmitz SF, Uitger U, Klingbiel D, Strasser F (2012) Electronic monitoring of symptoms and syndromes associated with cancer: methods of a randomized controlled trial SAKK 95/06 E-MOSAIC. BMC palliative care 11:19
6. Bruera E, Kuehn N, Miller MJ, Selmser P, Macmillan K (1991) The Edmonton Symptom Assessment System (ESAS): a simple method for the assessment of palliative care patients. J Palliat Care 7:6-9

7. Buxton J, White M, Osoba D (1998) Patients' experiences using a computerized program with a touch-sensitive video monitor for the assessment of health-related quality of life. Qual Life Res Int J Qual Life Asp Treat Care Rehab 7:513-519

8. Chan CW, Tam W, Cheng KK, Chui YY, So WK, Mok T, Wong C, McReynolds J, Berry DL (2011) Piloting electronic self report symptom assessment - cancer (ESRA-C) in Hong Kong: a mixed method approach. Eur J Oncol Nurs 15:325-334

9. Cox A, Illsley M, Knibb W, Lucas C, O'Driscoll M, Potter C, Flowerday A, Faithfull S (2011) The acceptability of e-technology to monitor and assess patient symptoms following palliative radiotherapy for lung cancer. Palliat Med 25:675-681

10. Cull A, Gould A, House A, Smith A, Strong V, Velikova G, Wright P, Selby P (2001) Validating automated screening for psychological distress by means of computer touchscreens for use in routine oncology practice. Br J Cancer 85:1842-1849

11. Detmar SB, Aaronson NK (1998) Quality of life assessment in daily clinical oncology practice: a feasibility study. Eur J Cancer 34:11811186

12. Detmar SB, Muller MJ, Schornagel JH, Wever LDV, Aaronson NK (2002) Health-related quality-of-life assessments and patientphysician communication: a randomized controlled trial. JAMA 288:3027-3034

13. Doyle C, Crump M, Pintilie M, Oza AM (2001) Does palliative chemotherapy palliate? Evaluation of expectations, outcomes, and costs in women receiving chemotherapy for advanced ovarian cancer. J Clin Oncol 19:1266-1274

14. Emanuel EJ, Wendler D, Grady C (2000) What makes clinical research ethical? JAMA 283:2701-2711

15. Fisch MJ, Titzer ML, Kristeller JL, Shen J, Loehrer PJ, Jung S-H, Passik SD, Einhorn LH (2003) Assessment of quality of life in outpatients with advanced cancer: the accuracy of clinician estimations and the relevance of spiritual well-being-a Hoosier Oncology Group Study. J Clin Oncol 21:2754-2759

16. Gough IR, Dalgleish LI (1991) What value is given to quality of life assessment by health professionals considering response to palliative chemotherapy for advanced cancer? Cancer 68:220-225

17. Gwaltney CJ, Shields AL, Shiffman S (2008) Equivalence of electronic and paper-and-pencil administration of patient-reported outcome measures: a meta-analytic review. Value Health 11:322-333

18. Hjermstad MJ, Lie HC, Caraceni A, Currow DC, Fainsinger RL, Gundersen OE, Haugen DF, Heitzer E, Radbruch L, Stone PC, Strasser F, Kaasa S, Loge JH (2012) Computer-Based symptom assessment is feasible in patients with advanced cancer: results from an International Multicenter Study, the EPCRC-CSA. Journal of pain and symptom management

19. Hollen PJ, Gralla RJ, Stewart JA, Meharchand JM, Wierzbicki R, Leighl N (2013) Can a computerized format replace a paper form in PRO and HRQL evaluation? Psychometric testing of the computer-assisted LCSS instrument (eLCSS-QL). Support Care Cancer 21:165-172

20. Kaasa S, Loge JH, Fayers P, Caraceni A, Strasser F, Hjermstad MJ, Higginson I, Radbruch L, Haugen DF (2008) Symptom assessment in palliative care: a need for international collaboration. J Clin Oncol 26:3867-3873

21. Kearney N, Kidd L, Miller M, Sage M, Khorrami J, McGee M, Cassidy J, Niven K, Gray P (2006) Utilising handheld computers to monitor and support patients receiving chemotherapy: results of a UK-based feasibility study. Support Care Cancer 14:742-752

22. Laugsand EA, Jakobsen G, Kaasa S, Klepstad P (2011) Inadequate symptom control in advanced cancer patients across Europe. Support Care Cancer 19:2005-2014

23. Michael M, Hedley D, Oza A, Feld R, Pintilie M, Goel R, Maroun J, Jolivet J, Fields A, Lee IM, Moore MJ (2002) The palliative benefit 
of irinotecan in 5-fluorouracil-refractory colorectal cancer: its prospective evaluation by a multicenter Canadian trial. Clin Color Cancer 2:93-101

24. Mullen KH, Berry DL, Zierler BK (2004) Computerized symptom and quality-of-life assessment for patients with cancer part II: acceptability and usability. Oncol Nurs Forum 31:E84-89

25. Oliver DR, Demiris G (2004) An assessment of the readiness of hospice organizations to accept technological innovation. J Telemed Telecare 10:170-174

26. Passik SD, Kirsh KL (2000) The importance of quality-of-life endpoints in clinical trials to the practicing oncologist. Hematol Oncol Clin North Am 14:877-886

27. Ruland CM, Holte HH, Roislien J, Heaven C, Hamilton GA, Kristiansen J, Sandbaek H, Kvaloy SO, Hasund L, Ellison MC (2010) Effects of a computer-supported interactive tailored patient assessment tool on patient care, symptom distress, and patients' need for symptom management support: a randomized clinical trial. J Am Med Inform Assoc 17:403-410
28. Taenzer P, Bultz BD, Carlson LE, Speca M, DeGagne T, Olson K, Doll R, Rosberger Z (2000) Impact of computerized quality of life screening on physician behaviour and patient satisfaction in lung cancer outpatients. Psycho-oncology 9:203-213

29. Velikova G, Brown JM, Smith AB, Selby PJ (2002) Computer-based quality of life questionnaires may contribute to doctor-patient interactions in oncology. Br J Cancer 86:51-59

30. Velikova G, Wright P, Smith AB, Stark D, Perren T, Brown J, Selby P (2001) Self-reported quality of life of individual cancer patients: concordance of results with disease course and medical records. J Clin Oncol 19:2064-2073

31. Wilkie DJ, Judge MK, Berry DL, Dell J, Zong S, Gilespie R (2003) Usability of a computerized PAINReportIt in the general public with pain and people with cancer pain. J Pain Symptom Manag 25:213-224

32. Wright EP, Selby PJ, Crawford M, Gillibrand A, Johnston C, Perren TJ, Rush R, Smith A, Velikova G, Watson K, Gould A, Cull A (2003) Feasibility and compliance of automated measurement of quality of life in oncology practice. J Clin Oncol 21:374-382 